The repeated narration of specific events and identity stability in mid-life

\author{
Kate C. McLean ${ }^{1}$ (Kate.McLean@wwu.edu) \\ Christin Köber² (christinkoeber@nyu.edu) \\ Kristin Haraldsson ${ }^{1}$ (haraldk@wwu.edu) \\ ${ }^{1}$ Western Washington University, corresponding author \\ ${ }^{2}$ New York University, Abu Dhabi
}

Acknowledgements: We thank the other authors in this volume for their comments and criticisms on an earlier draft of this manuscript. 


\begin{abstract}
In this case-study based qualitative analysis, we sought to examine the question of stability in narrative identity. We did this by examining four mid-life adults, who each provided two life story interviews, four years apart as a part of a larger study. Two of these participants were deemed 'low repeaters,' for having little repetition of manifest narrative content (i.e., actual events repeated at the two interviews). Two were deemed 'high repeaters' for having a much greater number of repeated manifest content. Our analysis focused on similarities between the low repeaters and the high repeaters, as well as the differences between them, with the aim of theory-building in the domain of narrative identity stability. Broadly, our analyses revealed that low repetition can occur for a variety of reasons including methodological factors, the occurrence of new life events between interviews, and traumatic history. High repetition can also occur for multiple reasons including performative concerns and conformity to cultural norms regarding life scripts. We offer these analyses as fodder for building theory regarding the phenomenology of identity stability, and its meaning for psychological functioning.
\end{abstract}




\section{The repeated narration of specific events and identity stability in mid-life}

A woman in mid-life recounts the horror of being raped as one of the most negative memories of her adolescent years. She reports her experience of fear, devastation, and emotional and physical withdrawal. It changed her perspective on people; it changed how she engaged with the world. Another woman recounts her experience of being diagnosed with breast cancer as the low point of her life. Although it was devastating, the prognosis and conclusion of the story were positive, and this event seems not entirely central to her identity. Indeed, it is one of several events she considers describing in response to the low point question in the interview in which she participated. Five years later, the first woman mentions nothing about the rape, and the second woman recounts the breast cancer story almost verbatim. What does it mean for the identities of these women that one repeats her stories over time, and one does not? In particular, what does it tell us about the stability of identity over time? To address these questions, we examine the life stories of these two women, along with two other participants who participated in a larger longitudinal study of mid-life adults.

The question of stability in identity is not a new one. Many thinkers on the topic have written about the need to know, integrate, and find consistency within the self (Locke, 1996, James, 1890; Mead, 1934; Schechtman, 2003; 2005; Swann, 1990) - all terms that suggest some kind of self-stability. Further, people often report, or feel, that they experience this stability feeling as if they are the same person across time and context, particularly as they move out of adolescence and into adulthood. Thus, it makes sense that some degree of stability in our identities is healthy: at a very basic level, we need to predict our future behavior, and be accountable for our past behavior to function in the social world (Pasupathi, Brubaker, \& Mansour, 2007; Schechtman, 2003; 2005). However, it also makes intuitive sense that 
stagnation or rigidity is not optimal. That is, over the life course we expect changes to occur in our psychological experience, and certainly in the events and contexts of our lives, as well as in our evaluations of them, so some movement should also be adaptive.

These musings are the motivations for our take on this project, and they are in contrast to much of the existing work on narrative identity development, which has focused on how identities change over time, and less so on what remains the same over time (see McLean, Syed, Haraldsson, \& Lowe, 2019), despite stability being a central question of development. To examine this question of identity stability, we have decided to begin with a focus on one type of stability, which is the repetition of specific life events - the two women with which we began this paper give us different examples of this. We will examine potential reasons for the inclusion and exclusion of prior events in the life story. We will also examine how continuity is established without the repetition of specific events. Our goal is to employ qualitative methods that enable refinement of the construct of stability in narrative identity via the deep and rich analysis of manifest event content (i.e., specifically recalled events), as well as autobiographical

processes (i.e., how events are narrated), and themes (i.e., general topical areas) in four case studies.

\section{Narrative Identity}

Narrative identity is defined as a story constructed by individuals within the supports and confines of the larger culture, which weaves together a narrative of past experiences, and how those experiences have brought them to their current place (e.g., McAdams, 1993). That is, individuals selectively recall and reflect on past events that are particularly salient to them, and that help to explain who they are. 
Our current understanding of this construct comes from extensive research showing that young children can tell stories in relatively coherent ways, with the assistance of expert storytellers (Fivush, Haden, \& Reese, 2006), that by middle childhood an understanding of the cultural concept of biography is known (Bohn \& Berntsen, 2008; Habermas, 2007), and that across adolescence there is an increase in the ability to reason about one's life in ways that build a narrative identity (Habermas \& Reese, 2015). We also know that being able to tell a story in which events are coherently narrated, coupled with explanations for how those events are meaningful to the self, is related to psychological well-being (see Adler, Lodi-Smith, Phillipe, \& Houle, 2016). Thus, this construct is a developmentally meaningful component of healthy adjustment.

By far, the bulk of research on narrative identity has focused on processes of development. That is, the constructs that have been linked to age-related change and well-being are typically capturing aspects of reasoning or how events are constructed or narrated, as opposed to the analysis of the events themselves (Galliher, McLean, \& Syed, 2017). Although these processes have been shown to be critical components of development and adjustment, the rich method of eliciting narrative accounts of a life, leaves quite a bit of data unexamined - the data concerning what the events are actually about. Recently, researchers have argued that examining the event content of narratives is an important component of the scientific process of description (Galliher et al., 2017; McLean, Syed, Yoder, \& Greenhoot, 2014; McLean, Syed, \& Shucard, 2016). Another reason to examine content is that it allows us to examine aspects of the self that remain, shift, and fade over time.

The idea that the events themselves may be part of this stability has received relatively little attention (for exceptions see Drivdahl \& Hyman, 2014; Josselson, 2009; McAdams, Bauer, 
Sakeda, Anyidoho, Machado, Magrino-Failla, White, \& Pals, 2006; Mishler, 2004; Syed \& Azmitia, 2010; Thorne, Cutting, \& Skaw, 1998). However, the data that do exist are instructive. In a study of life story memories (e.g., high points, low points), McAdams et al. (2006) found meaningful stability in some narrative constructs (e.g., emotional tone), and change in places that make theoretical sense (e.g., personal growth), but relatively little repetition of specific events over a 6-month (23\% repeated events) and 3-year assessment period (17\% repeated events). Over a 6-month study of relationship memories, Thorne, Cutting, and Skaw (1998) found relatively little repetition in a similar sample (12\% repeated events). Finally, Syed and Azmitia (2010) found that $18 \%$ of college students' stories about ethnicity-related experiences were twice-told over an 18-month period. Further, those who told the same story at two time points were over-represented in the groups who remained stable or decreased on ethnic identity exploration, suggesting that event-repetition may be representative of stagnation, rather than healthy stability ${ }^{1}$. Overall, these results resonate with Thorne et al.'s (1998) suggestion that these important life narratives are 'examples,' rather than 'essential landmarks.' That is, one may have several low points to choose from, and one given low point event may not necessarily be essential to who one is.

However, these studies were all done with emerging adults - a time of identity development, in which the self should be in flux. So as a life story develops across adulthood, do landmarks begin to play a more important role in facilitating a sense of stability? Indeed, Josselson (2009) suggested that there might be more consolidation, or repetition, of narratives as

\footnotetext{
${ }^{1}$ Interestingly, some of the evidence for stagnation comes from a study within a particular domain - ethnic identity, which begs the question of whether domain-repetition is different from repetition of larger life story events (e.g., childbirth). This is not something we can address in the present study, but may be fodder for future research.
} 
one ages, which was empirically substantiated in a longitudinal study on entire life narratives (Köber \& Habermas, 2017).

Further, as one experiences more of the canonical events in a life course (e.g., graduation, marriage, childbirth), those events may become privileged in repetition as they are the events that are supposed to be in a biography (Arnett, 2017; Habermas, 2007; McLean \& Syed, 2015; Rubin \& Berntsen, 2003). This phenomenon has been termed a biographical master narrative (McLean \& Syed, 2015), representing a cultural script for forming a life story. As mid-life adults will have had the opportunity to experience more of these expected events, we might see more repetition in them (see Köber \& Habermas, 2017). Indeed, Dunlop, Guo and McAdams (2016) reported longitudinal increases in the frequency of redemptive stories in life story memories for a sample of college students. They suggested that this might represent individuals coming to learn the expected narrative patterns of their culture - in this case the American value on redemption. Relatedly, Drivdahl and Hyman (2014) found greater cross-time consistency in relationship memories for more commonly recalled events, such as first dates. In the present study we evaluated whether the degree to which life script events were present in the life story interviews, and whether such presence was connected to event repetition.

\section{The Present Study}

Despite our focus on the repetition of event content, our initial thoughts about this project were that a sense of stability in the self, or personal continuity, could be established for those with high or low repeated manifest content, and that repeated content may not necessarily signal a healthy sense of stability. For example, for the low repetition cases, we might see repetition established with similar themes across time points, or a high degree of reflection that explains 
new content. High repetition could also signal a stability that is static, or even stuck, if it is not coupled with reflective processes (see Syed \& Azmitia, 2010).

In short, in the present study, our aim was to examine these ideas in four cases in order to generate theory and ideas about the notion of repeated narration and identity stability. The primary questions we asked of these cases were: 1) How does repeating events across time connect to the communication of a stable identity? 2) How is stability established without repeating events?

\section{Methods}

The overall methods are described in the introduction to this issues, and the study was approved by the Northwestern University Institutional Review Board, STU00001801MODCR0002.

Our framework for analyzing these data comes from a thematic analysis approach, involving reading and re-reading the interviews until a saturation point is reached (i.e., no new themes emerge) (Braun \& Clarke, 2006; see also Wertz, Charmaz, McMullen, Josselson, Anderson, \& McSpadden, 2011). We chose this framework because of our aim of guiding new lines of inquiry, and the aim of this kind of analysis is to construct categories from the data that can guide, or inform, future lines of research.

All three authors participated in the analyses of the interviews. One is German, two are American, one was a post-doc, one was a new graduate student, and one a professor. None of us had relations with the interviewees, though one of us had read some of the interviews prior but had done no formal analysis. In terms of our own reflexivity, there was a power imbalance in a group composed of a senior professor, post-doc, and student, so we worked to make sure each of our voices and impressions were incorporated into our analyses. We also noted the differing 
interpretations of cases given cultural expectations and language use of the interviewees. The two American authors sought to clarify language use and cultural norms at the most basic level, so as not to limit psychological analysis brought forward by the non-American in our working group.

We structured our readings in three stages. First, the three authors read all eight interviews independently, and in their entirety. Our aim in this initial reading was to get the lay of the land and to note anything that stood out to us (eight interviews per session). Our next stage involved reading two cases at a time (four interviews per session), pairing a high and low repeater for contrast. In the third stage, we read the two low repeaters together, and then the two high repeaters (four interviews per session). After each session of reading (eight or four interviews, depending on the stage), we met as a group to discuss our impressions, taking notes on emerging themes and ideas. These themes and ideas were re-evaluated at each meeting, and became the source of our analyses.

After the first stage, transcripts were coded for presence or absence of events that are part of the life script across multiple cultures, including the U.S. (e.g., beginning school, first job, having children; Berntsen \& Rubin, 2004), or the love life script that was based on an American sample (e.g., first kiss, first break-up, getting married; Dunlop et al., 2017). Events that occur in both scripts were considered only once. After a test trial with one transcript, the second and third author coded the remaining seven transcripts independently (kappa range across interviews $=.75$ - .87). Disagreements were resolved by discussion.

\section{Case Analyses}


We divide the results by reporting our analyses of the commonalities between the high repeaters, Leah and Dennis, followed by their distinctions; we do the same for the low repeaters, Abigail and Renee.

\section{Commonalities amongst the High Repeaters}

We noted three clear similarities between these two cases. First, the high repeaters reported rather typical life courses, in terms of life script events. They had both narrated relatively predictable lives with relatively benign childhoods (with some exceptions), followed by higher education, romance, marriage, careers, children. This was confirmed in the analyses of life script events, in which the high repeaters had more than double the number of life script events compared to the low repeaters. The high repeaters had an average (across the two interviews) of 18 (Leah) and 26.5 (Dennis) life script events, whereas the low repeaters had an average of 8.5 (Abigail), and 10.5 (Renee). Also, Leah and Dennis reported more life script events at the second interview, suggesting that life scripts might compound stability in repetition (see Drivdahl \& Hyman, 2014; Köber \& Habermas, 2017). Life script events can serve as a type of cognitive schema (Koppel \& Bernstein, 2014) that allows for better encoding and recall of episodic memories (see Brewer \& Nakamura, 1984), allowing our high repeaters to have better retention and recall of such events.

Second, we noted the rehearsed nature of the high repeater's stories. They were remarkably coherent and well-told, and we surmised that they might have been told to others with some frequency. This interpretation was supported in their interviews. For example, Leah noted that she had written about her experiences, and is a writer by trade, creating greater opportunities for solidifying her stories through repeated writing and telling (though at second interview she reported that she did not remember what she had shared at the first). She noted 
“...I'm a writer and this is -- that's why I like what we've done so far because I could...think it through and I could write it out and then put it on the survey."

Third, we wondered if this presumed rehearsal might reflect a high need to be heard or validated, particularly with Dennis. These stories might have even been used for impression management - painting a positive picture of the self, with these normative and well-formed stories. For example, Dennis talked about hearing that his father had just died on the day of his daughter's wedding, and the need for composure:

I was completely composed cause that's the way it had to be, and just you're kind of like - I guess it's maybe like when you're in battle or something. You just got to do what you got to do...it was, it was sublime. We walked her down the aisle. The reception was beautiful. I did a really class toast that I had spent months trying to decide what to say and did it just the way I wanted. Was composed. Did the father/daughter dance and was composed.

Here we have a need for composure that many people might also desire. But the externality of this story - things looking good from the outside, which also happens to conform to the cultural script of a happy wedding day: the aisle, the toast, the dance - also appears meaningful.

The conformity to the life script, coupled with high rehearsal, and impression management paints a picture of high repetition as functioning to create a sense of stability and predictability for the self, but also for others. Alignment with the master narrative can create a sense of connection and belonging to the larger cultural group (McLean \& Syed, 2015). Distinctions between the High Repeaters 
Despite their similarities, there were also some marked differences between these two cases. Our first observation was that Dennis had clear themes, repeated across his two interviews, concerning achievement and heroism. His most well-developed stories are about his early successes and good times. His story about his first kiss with his wife seems to be about winning the girl, and his story about being dumped by a former girlfriend becomes his life low point because the other guy gets her - he loses. He also tells stories of taking care of his aging parents and managing his emotions about his father's death on the day of this daughter's wedding with an emphasis on his abilities to be in control and to fulfill a certain role in the family (see excerpt above). For example, he reported that "I never cried or, you know, I, I wanted to have control of my emotions simply independent of what was going on with my dad..."

The narration of these experiences may sustain a positive view of himself as someone who can successfully master difficult situations and take care of others, which may also be indicative of a highly masculine gendered identity. This is consistent with the relative lack of attention to communal themes and relationships in his overall story (e.g., Fivush \& Marin, 2018; Grysman \& Hudson, 2013). For example, the story of his father dying on the day of his daughter's wedding is entirely about his own role, rather than his mother (his father's widow), his daughter, or anyone else who may have been affected. In fact, he has remarkably little detail in any part of his interview about his wife and daughters, primarily focusing on himself and his career (in quite stark contrast to the other three cases, notably all of whom are women). Thus, he talks remarkably little about how others have touched him (with the exception of his volatile father - see Singer, this volume). 
Notably, even with new career events to discuss at the second interview, Dennis continues to repeat the same stories, which gave us the impression of static life story. Indeed, the stability of specific stories (e.g., daughter's wedding day) and themes (e.g., achievement) gave us the sense that he was stuck, and perhaps hindered in the potential for mid-life development. It is also possible that these achievements are especially salient during a time in which this part of his self was threatened by job loss. That is, he may be gripping more tightly to those past events to protect against current threat (see Josselson, 2004).

In contrast, Leah is far more reflective about her stories; she thinks about her life story a lot. Her stories, though repeated, are filled with autobiographical reasoning processes, making them appear less stuck and rigid, but rather refined, as well as accessible and functional for communicating her identity. As with Dennis, she also had a higher frequency of life script events than the low repeaters, and she gave us a potential clue as to why some might do this more than others. On multiple occasions she noted her proclivity for watching TV, and we wondered if her fit with the biographical master narrative might be related to the framework she has internalized from the cultural medium of media, of which she seems to make liberal use. ${ }^{2}$

It is also possible that there is some intra-individual variability in the function of her repetition; each of the stories could serve its own purpose. The story of her daughter's birth is clearly a good story - a solitary moment of watching a soap opera and enjoying a glass of wine from her hospital bed could be the perfect anecdote for a dinner party. It is funny, sweet, and aligns neatly with the biographical master narrative. Her father's death is clearly important, and is tied to her own wedding, and the linkage between two important events may increase the

\footnotetext{
${ }^{2}$ Initially, we thought that she may not have had a lot of new events to narrate at the second interview, but she did have a career change and one of her daughters got married.
} 
likelihood of repetition (this may also be a reason for Dennis's repetition of his father's death, and his daughter's wedding). Her story about the breast cancer diagnosis almost seems an obligatory 'Oprah story' (e.g., 'here is my trauma'), but she does not elaborate its meaning in her life, besides some guilt over what it brings to her family. Her story about her daughter's anorexia is notable for the powerlessness and guilt that she feels. The story still appears unresolved, as if it is still burning a hole in her life story. And given that this story is still ongoing (her daughter is not fully recovered), it makes sense that it was repeated (see also Zeigarnik, 1967 - we thank Jefferson Singer for noting this connection).

In sum, despite these repetitions, we suggest that Leah does not have a static identity. Her autobiographical reasoning creates some dynamism, as if she is working on these stories, or at least thinking about how they fit within her larger life story. Though Dennis was coherent, he was not a high reasoner, so his repetition was missing the kind of evaluation and interpretation that makes a story more dynamic.

\section{Commonalities Amongst the Low Repeaters}

Central to the current analyses, our multiple reads of these cases did not lead us to conclude that these two women had remarkably inconsistent or unstable identities. In fact, the most important lesson drawn from these cases may be that repeated content is not necessary for identity stability. We found four major similarities in these cases.

First, our main reason for seeing stability in these cases was the strong repetition of themes in both of these cases, particularly themes related to their values. For example, Renee had consistent themes at both interviews of resilience, perseverance, racism and sexism, love of learning, recovery, and a positive outlook that brought a familiarity to her stories. At the first interview she said: 
My greatest challenge was my addiction....I went to a 12-step program, got a sponsor, and continued to work on changing my life.... Well, it gives me an opportunity to really look at life as, as a new beginning. Every day is a new beginning. And I have a opportunity to either be positive or negative every day. So it gives me a opportunity to not react so much with the attitude of negativity. So I always try to be positive with people I encounter all the time so.

And at the second interview:

So I believe that every day is a spiritual experience and a miracle. Each day God allows me the breath to breathe, that's a miracle. So I simplified my life to acknowledge the miracle of living and enjoying people. I feel that people are miracles. Each day that you get an opportunity or take the time to talk or listen to someone, that's a miracle. I've learned how to just simplify my life and accept the -- God as my miracle and it's like I know that I'm one with God. So in order to be like that, that means I accept people for who they are and not judge them. So each day that I do that, that's a miracle for me. Abigail also had consistent themes, including family, pride in her children, and doing good work - leading a principled life. Both women talked extensively about the centrality of religion to their lives. Their religious beliefs and practices might bring them stability and grounding, lessening the need for grounding from specific events. This emphasis on values may also be something of note in mid-life, a time when the generative need to pass on one's legacy may make values more central to identity (e.g., Erikson, 1963).

Second, both women had fluctuations in their lives over the assessment period, including new events, which may have contributed to a lack of repetition. At the first interview, Renee had filed for divorce the day before the interview, an event that may have put her in a state of 
disequilibrium, and shaded the events that she recalled. At the second interview, she no longer mentioned her divorce, but had achieved major job successes and was more focused on those events (also due to added interview questions about career). Abigail reported several important new events since the first interview, which included her husband being diagnosed with an incurable illness, and the death of her mother.

Third, as mentioned in the section above, there was a difference between low and high repeaters in terms of the inclusion of life script events in their narratives. However, we began to question which life script we were using, as we read and re-read these low repetition cases. We noted that these two cases belong to two distinct cultural groups in the United States - Jewish Americans and African Americans - groups that may have alternative cultural narratives ${ }^{3}$. Thus, their lives might be following a different life script. Indeed, Abigail has a life story of immigration, the centrality of religion (she is a docent at a holocaust museum, a position that is quite meaningful to her), success of self and children through opportunity and hard work, redemption, and visiting Israel, which might fit with a Jewish American life script. It is certainly not antithetical to an American life script, but the recency of familial immigration and historical trauma may shade it. Abigail also reported a number of events about other people - which are not part of life script events. For example, her low point is other people being afraid she was lost on a family trip.

Renee reported events that might be consonant with an African American historical and intergenerational script - slavery, sharecropping, migration north, a strong maternal figure, the

${ }^{3}$ We note that Leah is also Jewish, and her religion is important to her as well. 
political assassinations of the 1960s, and the oppressive forces of racism (and sexism) ${ }^{4}$. Thus, an analysis using a different cultural life script might have shown higher conformity.

Fourth, we found a striking humility in these two cases. Renee emphasized her acceptance of people (see above) and as did Abigail at the first interview, in talking about her father's death, said she felt:

Inspir[ed] ...to have patience, to not get angry at people and to work hard, to not look -not look down on anybody, to treat anybody as an equal.

And at the second interview:

I think I'm, I'm a selfless kind of person trying to do the right thing, not thinking about myself. Whereas other people are looking at things and trying to see how it can benefit them.

Humility may allow for other kinds of events to come in and out, because the self is less overpowering. In contrast, higher egocentrism might make specific events feel more central to the self, and thus harder to let go.

In sum, although there was little repeated content over time, both of these women showed stability in the ways in which they communicated themselves. However, the lack of repeated events may exist for different reasons for these two women.

Distinctions between the Low Repeaters

The first distinction between them is the severity of the events. Renee has had a remarkable number of tragedies and traumas in her life (poverty, rape, robbery, familial violence, addiction, physical accidents, racism, sexism, divorce, thwarted educational attainment,

\footnotetext{
${ }^{4}$ This participant was also in recovery, and may be employing a script consonant with Alcoholics Anonymous.
} 
intergenerational trauma). The word "chaos" is repeated multiple times in her interview. Thus, her lack of repetition may be due to the number of traumas she has experienced, such that she may not want to integrate all of them into her identity. Or she may not have been able to find the psychological calm and space to consider integration (we thank Jefferson Singer for this interpretation). Her resilience is forward thinking, so her goal may not be to make sense of the past in a way that integrates specific events into an increasingly solidified story. Indeed, she says that her life story is constantly changing, and that she has a "commitment to change."

There are also some practical reasons for the lack of repetition, best exemplified in Abigail's interview. First, she remembers some of what she shared at the first interview, and says she wants to share new events, perhaps in part because she has the same interviewer at both time points (see Pasupathi \& Wainryb, this issue). Second, as mentioned above, she has new stories to tell, and many of them are quite disruptive (e.g., mother's death, husband's incurable diagnosis, and a major family conflict). Indeed, we found her to be more introspective at the second interview, suggesting that she might be doing more identity work to make sense of the disruptions that have come her way between interviews.

Finally, these two cases teach us something about trajectories of identity development, and how periods of disequilibrium may influence a lack of event repetition, though with quite opposite trajectories. The end of the first interview includes questions about whether one has changed or stayed the same. In answering this question Abigail is entirely invested in stability, defining herself by it, and Renee defines herself by her "commitment to change." At this point in their lives they may have been in very different places in terms of their identities - Abigail was cruising, and Renee had just filed for divorce. By the second interview, their trajectories have shifted. Abigail has been rocked by change, and Renee has had a chance to resolve the 
trauma of her divorce 5 . Indeed, she is more resolved and positive at the second interview (after which she has also achieved some career success). In contrast, Abigail has experienced events that challenge her future hopes and dreams (e.g., husband's diagnosis), and her integrity (e.g., fight with sister-in-law); these events bring a tinge of cynicism and introspection to her interview, not seen at the first interview. Thus, we see these trajectories of instability-to-stability in identity (Renee), and stability-to-instability (Abigail).

\section{Conclusions and Implications for the Study of Identity and Personality Development}

The literature on narrative identity has operated under the theoretical assumption that identity is constructed by recounting the events of one's life (see Mishler, 2004). No one has said that events should be the same, but privilege has been given to the events or 'lived experience' in our methodologies and theoretical writings. However, when we look at the empirical measurement of narrative identity, the great majority of research has not addressed the degree to which it is the manifest content of those specific events that constitute identity. Instead privilege has been given to ways of telling a story (e.g., autobiographical reasoning processes). Consistent with that, it is clear from these analyses that one does not necessarily need repetition of specific events to communicate a stable identity.

It is possible that identity stability comes from multiple sources, and individuals may vary in which sources work for them. In other words, for some people, event content is central to identity continuity, and for others it is the themes of their stories (e.g., values) that defines them. There could also be individual differences in the use of the biographical master narrative, or the need to use it; some people may feel the press to conform less strongly than others (see

\footnotetext{
${ }^{5}$ At the second and third year assessments she lists one of her goals as reuniting with her husband, but this goal is absent by the fourth year.
} 
McLean et al., 2019). Further, even when events are retained, the meaning of them can change, a process that would suggest continued identity development (Josselson, 2009). Josselson (in press) eloquently uses a kaleidoscope metaphor to describe the shifting arrangements and patterns of events in the life story. The death of one's father (as some participants detailed) may never leave the life story, but its meaning may shift, reflecting various forms of coping and adaptation through the processes of autobiographical reasoning.

Developmentally, we would also expect less continuity from those in earlier stages of life (see Köber \& Habermas, 2017; McLean, 2008; Singer, Rexhaj and Baddeley, 2007). As individuals practice and build a larger story earlier in the life course, events will fall in and out of that story. With more life experience, comes more events - and perhaps particular events that will form the template of many people's life stories - such as those related to career, committed romance, and the building of a family (especially if conforming to the life script). Thus, the frequency of repetition should be less in early life, but so should the meaning of it. Repetition may be more adaptive in later life when that story becomes more solidified; early on, repetition could signal a kind of foreclosure.

In conclusion, we see the role of actual events - at least from a stability perspective - as one potential source of stability, but certainly not the only one. And repeated content can reveal both the landmarks of a life, and a rigidity that impedes development. For some, finding ways to unlock the stories that squelch movement might allow the development of a sense of stability in other ways. And for others the landmarks will remain, but the meaning of them can still be alive. 


\section{References}

Adler, J. M., Lodi-Smith, J., Philippe, F. L., \& Houle, I. (2016). The incremental validity of narrative identity in predicting well-being: A review of the field and recommendations for the future. Personality and Social Psychology Review, 20(2), 142-175. doi: $10.1177 / 1088868315585068$

Arnett, J. J. (2017). Life stage concepts across history and cultures: Proposal for a new field on indigenous life stages. Human Development, 59(5), 290-316. doi:10.1159/000453627

Bluck, S., \& Alea, N. (2009). Thinking and talking about the past: Why remember? Applied Cognitive Psychology, 23, 1089 1104. doi:10.1002/acp.1612

Berntsen, D., \& Rubin, D. C. (2004). Cultural life scripts structure recall from autobiographical memory. Memory \& Cognition, 32(3), 427-442. doi:10.3758/BF03195836

Bohn, A., \& Berntsen, D. (2008). Life story development in childhood: The development of life story abilities and the acquisition of cultural life scripts from late middle childhood to adolescence. Developmental Psychology, 44(4), 1135-1147. doi:10.1037/00121649.44.4.1135

Bower, G. H. (1981). Mood and memory. American Psychologist, 36, 129-148. doi:10.1037/0003-066X.36.2.129

Braun, V., \& Clarke, V. (2006). Using thematic analysis in psychology. Qualitative Research in Psychology, 3(2), 77-101. doi:10.1191/1478088706qp063oa

Brewer, W. F., \& Nakamura, G. V. (1984). The nature and functions of schemas. In R. J. Wyer, $\mathrm{T}$.

K. Srull, R. J. Wyer, T. K. Srull (Eds.), Handbook of Social Cognition, 1, (pp. 118-160). Mahwah, NJ: Lawrence Erlbaum Associates Publishers. 
Drivdahl, S. B. \& Hyman, I. E. (2014). Fluidity in autobiographical memories: Relationship memories sampled on two occasions. Memory, 22, 1070-81. doi: $10.1080 / 09658211.2013 .866683$

Dunlop, W. L., Guo, J., \& McAdams, D. P. (2016). The autobiographical author through time: examining the degree of stability and change in redemptive and contaminated personal narratives. Social Psychological and Personality Science, 7, 428-436. doi: $10.1177 / 1948550616644654$

Dunlop, W. L., Hanley, G. E., McCoy, T. P., \& Harake, N. (2017). Sticking to the (romantic) script: an examination of love life scripts, stories, and self-reports of normality. Memory, 25(10), 1444-1454. doi:10.1080/09658211.2017.1316509

Erikson, E. H. (1993). Childhood and society. New York, NY: Nortion

Fivush, R., Haden, C. A., \& Reese, E. (2006). Elaborating on elaborations: role of maternal reminiscing style in cognitive and socioemotional development. Child Development, 77(6), 1568-1588. doi: 0.1111/j.1467-8624.2006.00960.x

Fivush, R., \& Marin, K. (2018). Development of a gendered narrative identity. In C. B. Travis, J. W. White, A. Rutherford, W. S. Williams, S. L. Cook, \& K. F. Wyche (Eds.), APA handbooks in psychology series. APA handbook of the psychology of women: History, theory, and battlegrounds (pp. 473-487). Washington, DC, US: American Psychological Association.

\section{http://dx.doi.org/10.1037/0000059-024}

Galliher, R. V., McLean, K. C., \& Syed, M. (2017). An integrated developmental model for studying identity content in context. Developmental Psychology, 53(11), 2011-2022. doi: $10.1037 / \operatorname{dev} 0000299$ 
Grysman, A., \& Hudson, J. A. (2013). Gender differences in autobiographical memory: Developmental and methodological considerations. Developmental Review, 33(3), 239272.doi: 10.1016/j.dr.2013.07.004

Habermas, T. (2007). How to tell a life: The development of the cultural concept of biography. Journal of Cognition \& Development, 8(1), 1-31. doi:10.1207/s15327647jcd0801_1

Habermas, T., \& Reese, E. (2015). Getting a life takes time: The development of the life story in adolescence, its precursors and consequences. Human Development, 58(3), 172-201. doi:10.1159/000437245

James, W. (1890). The principles of psychology. New York, NY: Holt.

Josselson, R. (2009). The present of the past: Dialogues with memory over time. Journal of Personality, 77(3), 647-668. doi:10.1111/j.1467-6494.2009.00560.x

Josselson, R. (2019). Narrative, identity, and identity statuses. To appear in D. P. McAdams, J. Tackett, \& R. Shiner (Eds.), The Handbook of Personality Development. New York: Guilford.

Köber, C., \& Habermas, T. (2017). How stable is the personal past? Stability of most important autobiographical memories and life narratives across eight years in a life span sample. Journal of Personality and Social Psychology, 113(4), 608-626. doi: $10.1037 /$ pspp0000145

Koppel, J., \& Berntsen, D. (2014). The cultural life script as cognitive schema: How the life script shapes memory for fictional life stories. Memory, 22(8), 949-971. doi:10.1080/09658211.2013.859269 
Mead, G. H. (1934). Mind, self and society. Chicago, IL: University of Chicago Press.

Locke, E. A. (1996). Motivation through conscious goal setting. Applied \& Preventive Psychology, 5(2), 117-124. doi:10.1016/S0962-1849(96)80005-9

McAdams, D. P. (1993). The stories we live by: Personal myths and the making of the self. New York, NY: William Morrow \& Co.

McAdams, D. P. (1997). The case for unity in the (post)modern self: A modest proposal. In R. Ash- more \& L. Jussim (Eds.), Self and identity: Fun-damental issues (pp. 46-78). New York, NY: Oxford University Press.

McAdams, D. P., Bauer, J. J., Sakaeda, A. R., Anyidoho, N. A., Machado, M. A., MagrinoFailla, K., \& ... Pals, J. L. (2006). Continuity and change in the life story: A longitudinal study of autobiographical memories in emerging adulthood. Journal of Personality, 74(5), 1371-1400. doi:10.1111/j.1467-6494.2006.00412.x

McLean, K. C. (2008). Stories of the young and the old: Reflections on self-continuity. Developmental Psychology, 44, 254-164.

McLean, K. C., \& Syed, M. (2015). Personal, master, and alternative narratives: An integrative framework for understanding identity development in context. Human Development, 58(6), 318-349. doi:10.1159/000445817

McLean, K. C., Syed, M., Haraldsson, K., \& Lowe, L. (2019). Narrative identity in the social world. To appear in P. Corr \& G. Matthews (Eds.), Handbook of Personality Psychology. Cambridge, UK: Cambridge University Press.

McLean, K. C., Syed, M., \& Shucard, H. (2016). Bringing identity content to the fore: Links to identity development processes. Emerging Adulthood, 5, 356 - 364.

doi: $10.1177 / 2167696815626820$ 
McLean, K. C., Syed, M., Yoder, A., \& Greenhoot, A. F. (2014). The Role of domain content in understanding identity development processes. Journal of Research on Adolescence, 26(1), 60-75. doi:10.1111/jora.12169

Mishler, E. G. (2004). Storylines: Craftartists' narratives of identity. Cambridge, MA: Harvard University Press.

Pasupathi, M., Mansour, E., \& Brubaker J., R. (2007). Developing a life story: Constructing relations between self and experience in autobiographical narratives. Human Development, 50(2-3), 85-110. doi: 10.1159/000100939

Rubin, D. C., \& Berntsen, D. (2003). Life scripts help to maintain autobiographical memories of highly positive, but not highly negative, events. Memory \& Cognition, 31(1), 1-14. doi:10.3758/BF03196077

Schechtman, M. (2001). Empathic access: The missing ingredient in personal identity. Philosophical Explorations: An International Journal for The Philosophy Of Mind And Action, 4(2), 95-111. doi: 10.1080/10002001058538710

Schechtman, M. (2005). Personal identity and the past. Philosophy, Psychiatry, and Psychology, 12(1), 9-22. doi:10.1353/ppp.2005.0032

Singer, J., Rexhaj, B., \& Baddeley, J. (2007). Older, wiser, and happier?: Comparing older adults' and college students' self-defining memories. Memory, 15(8), 886-898.

Syed, M., \& Azmitia, M. (2010). Narrative and ethnic identity exploration: A longitudinal account of emerging adults' ethnicity-related experiences. Developmental Psychology, 46(1), 208-219. doi:10.1037/a0017825

Swann, W. B., Jr. (1990). To be adored or to be known? The interplay of self-enhancement and self-verification. In ET Higgins \& RM Sorrentino (Eds.), Handbook of Motivation and 
Cognition: Foundations of Social Behavior, Vol. 2, pp. 408-448. New York, NY: Guilford Press.

Thorne, A., Cutting, L., \& Skaw, D. (1998). Young adults' relationship memories and the life story: Examples or essential landmarks?. Narrative Inquiry, 8(2), 237-268. doi:10.1075/ni.8.2.02tho

Wertz, F. J., Charmaz, K., McMullen, L.M., Josselson, R., Anderson, R., \& McSpadden, E. (2011). Five ways of doing qualitative analysis: Phenomenological psychology, grounded theory, discourse analysis, narrative research, and intuitive inquiry. New York, NY: Guilford Press.

Zeigarnik, B. (1967). On finished and unfinished tasks. In W. D. Ellis (Ed.), A sourcebook of Gestalt psychology, New York: Humanities press. 